\title{
The possible value of a gap year: A case study
}

\author{
M. Coetzee \\ Educational Psychologist \\ South Africa \\ e-mail: melinda.coetzee@gmail.com
}

\author{
S. Bester \\ Department of Educational Psychology \\ University of Pretoria \\ South Africa \\ e-mail:suzanne.bester@up.ac.za
}

\begin{abstract}
The taking of a 'gap year', immediately after completing their secondary school education, to explore life before embarking on formal studies or starting their career, is a growing phenomenon among young people in South Africa. This research study explores the experiences of three young people who engaged in a gap year and focuses on the influence that gap year had on their individual career decision-making process.

A case study design was used and the data was collected by means of semi-structured interviews, as well as lifelines and collages the participants created for the purpose. Finally, the three participants, who were consulted throughout the research process, also participated in the final analysis of the data. The outcome of this study revealed that the chief value of the gap year might be found in the personal growth it facilitated and the benefit of extra time that the young people have at their disposal before finalising their career decision-making process.
\end{abstract}

\section{BACKGROUND}

\section{The gap year}

The gap year, a growing trend in the career development of young people in the western world, conventionally occurs when they travel and work internationally, gaining experience in the global village before returning to their country of origin and starting their careers. The traditional definition of a gap year refers to one year taken off by young people between school and university to explore the world and career opportunities (Piddock 2004, 1), while a research report compiled by Jones (2004b, 24) defines the gap year as a break taken by a student that lasts anything from 3 to 24 months. While a gap year customarily involves travelling to another country to work, travelling overseas is not a prerequisite for a break to be considered a gap year. Engaging in a meaningful activity during the gap, such as working or travelling, rather than being on vacation, is a key element that separates a gap year 
from a holiday. According to Simpson $(2005,447)$ the gap year has changed in the last five years from a 'radical activity, dominated by charities and inspired by the travel of the hippie generation, to an institutionally accepted commercial gap year industry which helps form new citizens for a global age'.

The prevalence of commercial gap year companies as well as the large number of young people taking gap years is seen as evidence of the growing popularity of this practice (Simpson 2005, 447; Jones 2004a, 2). While the gap year has been popular in the United Kingdom (UK) for some time, it is quickly growing in popularity in other countries including the United States of America (USA) (Piddock 2004, 1).

In South Africa, concerns have been raised regarding the number of young people leaving the country, and the issue of the 'brain drain' is one fraught with controversy (Robinson 2003, 1). However, opinions exist that, in the case of the gap year, 'brain circulation' occurs as opposed to 'brain drain'; this implies that many young people and professionals return from gap years abroad with more experience, and with more to offer to their professions (Robinson 2003, 2; Asmal 2004, 1).

Due to the gap year's growing popularity in recent years, more attention is being given to this phenomenon. Whereas some accounts of gap year experiences can be found in current literature (Jones 2004a, 2-3; Gose 2005, 2; Piddock 2004, 2), very little research is to be found regarding the impact of the gap year on career development in general, and specifically regarding career decision-making. Existing literature is focused on American and British students and their perceptions of the gap year, but little information is available about the phenomenon amongst South African young people. This article will attempt to contribute to the knowledge base by focusing specifically on how the experiences of South African youth during a gap year influenced their career decision-making.

With traditional approaches to career counselling falling away, new means are being sought to guide and assist young people to cope with the challenge of finding a place in the global village. Different theories have emerged to address this deficiency, which include: the social cognitive career theory (SCCT) of Lent, Brown and Hackett; the cognitive information processing approach (CIP) of Peterson, Sampson, Reardon and Lentz; Hansen's integrative life planning theory (ILP); and, post-modern approaches (such as the narrative approach and constructivist career counselling) (Niles and Harris-Bowlsbey 2002, 70-92).

Brott $(2004,189)$ stresses the importance of the exploration of meanings and themes in the client's personal stories during career counselling, and post-modern career theories have emerged to address this need. Savickas $(1993,209)$ furthermore stresses the importance of encouraging self-affirmation and of facilitating career decision-making when engaging in post-modern career counselling, as opposed to traditional approaches, which rely on psychometric tests and on finding the 'best fit'. The focus on personal meaning is therefore an important aspect of post-modern career counselling.

This study attempted to avoid the pitfall of reductionism by utilising a constructivist technique in order to investigate gap year participants' construction of meaning and 
understanding. This could have implications for career counselling in South Africa. In doing so, the research also aimed to contribute to the growing body of research within the constructivist paradigm.

\section{Conceptual framework}

The experiences of the three participants were viewed through the lense of the post-modern approach to career development, which states that each individual constructs meaning in career development and career decision-making processes. Mkhize and Frizelle $(2000,1)$ state that career development research in South Africa is influenced by the Western value of individualism, and argue that those values are not culturally relevant to African society. They propose that a hermeneutic and dialogical approach provides a more relevant framework for understanding career development in South Africa, as it emphasises that career development results from exposure to various social and cultural perspectives. The post-modern approach of constructivism is therefore considered to be applicable, as it allows for contextual and personal factors, as described by the participant, to be taken into account. Constructivists assert that reality is relative and that research findings are created through the interaction between the researcher and research participants (Schurink 1998a, 240). Hence, this research was situated within a constructivist-interpretivist paradigm and data collection was conducted qualitatively.

The ontological assumption that informed this research was that both the researcher and the participants in this research socially construct reality. The epistemological assumption was that participants construct meanings based on their experiences and their interaction within the social context. As stated by Cohen, et al. $(2004,8-21)$ the epistemological and ontological assumptions inform the research method and design.

Further, the researchers took into account the career development theories of Krumboltz, and worked within the framework of the career life-span approach of Super. Krumboltz theorizes that various factors such as genetic, environmental, learning experience and task approach skills all contribute to the ability to make a career decision (Tolbert 1980, 86).

This research explored the meanings the three participants attached to their gap year experiences, and how those meanings influenced their individual career decision-making process. This is linked to the factor of 'task approach skills' (with specific focus on emotional responses) as identified by Krumboltz (Tolbert 1980, 86). This factor can also be viewed in light of its impact on self-concept, as informed by Super's theory (Super, Savickas and Super 1996, 170).

\section{METHOD}

\section{Participants}

Three participants were selected using purposeful convenience sampling. The criterion for inclusion in the study was that the participants had engaged in a gap 
year prior to the research being conducted. The criterion for 'engaging in a gap year' was informed by the definition of the gap year as stipulated in Jones (2004b, 24), whereby the gap year is defined as:

... any period of time between 3 and 24 months which an individual takes "out" of formal education, training or the workplace, and where the timeout sits in the context of a longer career trajectory.

The sample consisted of three young people, all of whom had completed a gap year between the ages of 18 and 21. One participant was male, and two female, and all come from a predominantly middle-class background. At the time of the study the participants were aged 26, 23 and 21 years old respectively. Their pre-gap year experience and education varied greatly, with one participant matriculating before engaging in a gap year, another ceasing her university studies to take a gap year, and one working before deciding to travel abroad for her gap year. The nature of the gap years also varied, two of the participants focussed on work and travel abroad, while another worked in South Africa. All of the research participants went into careers when they returned - one studied further at university, while the other two directly entered the workplace.

\section{Data collection and analysis}

Lifelines, semi-structured interviews and collages were used to gather data for this study, to draw on multiple sources of data, which resulted in rich and detailed descriptions (Babbie, Mouton, Vorster and Prozesky 2002, 282; Yin 2003, 97; Merriam 1998:28; Henning, Van Rensburg and Smit 2004, 42).

\section{Lifelines and interviews}

After the researchers had conducted their preliminary literature survey, the first round of data collection with the three participants was initiated: each participant first constructed their lifeline, an activity that was followed by a semi-structured interview. The lifeline is identified by Brott $(2004,142)$ as a post-modern career counseling technique aimed at revealing the participant's past and present life story. It is an interactive method where the counselor works with the client to construct a visual representation of his or her life to date and the important events, people and experiences that shaped each of their life stories. It is a technique that falls within the constructivist paradigm, as it allows participants to construct meaning and portray their personal experiences (Brott 2004, 138). The technique was explained to each participant, and they were allowed sufficient time to construct their lifeline, focusing specifically on their career path and career decision-making processes. The lifeline was then discussed with the participants.

The semi-structured interviews were based upon the information provided in the lifelines, which provided the basis of the semi-structured interview schedule that was conducted with each participant. Questions were asked based on the information that 
was provided by the participants, for example; 'And I see that then you decided to go to the UK. What were you hoping to get out of going to the UK?' and 'Let's start at the beginning and tell me about it [your lifeline]'. 'What sort of work did you engage in while you did the gap, while you were in the UK?' 'It seems that you've taken quite a few steps to get to where you are now, you've been trying different things. What was that like?' As pointed out by Kvale (1996, 62), interviews are characterised by the premise that knowledge is not external to the individuals involved, but is generated between individuals, often through conversations. This is echoed by Smith (1995a, 1), who states that the researcher tries, through the interviewing process, to enter the 'psychological and social world of the participant'. Each participant was then asked to construct a collage about anything regarding their gap year or proposed career, which would be discussed at a later stage in the research process.

\section{Collages and interviews}

In recent years educational researchers have been investigating the use of visual images in qualitative data collection (Novoa 2000, 21; Margolis 2000, 8). As Fischman $(2001,359)$ points out, visual sources offer an alternative way of perceiving and undertaking educational research. The collage was, therefore, selected as a research method for this study, as it allowed an alternative mode of communication with each participant - through the stimulation of the visual images. Each participant made a collage, which focused on an area of their gap year or proposed career development that they felt was important. Each participant was then asked to discuss and describe their collage and the reasons for choosing the images during the process of constructing the collages. For example, one of the collages contained a picture of a tree. When asked about the meaning of the tree, the participant said: 'It's how I see my mind, I have lots of space to grow, a very green tree.' When queried about the appearance of the words, 'education' and 'learning' that appeared throughout her collage, the same participant answered: 'It's the fact that I chose education as a teacher, it's the fact that you need to be properly educated for the jobs that you want to do, the fact that you need to be educated more about what the jobs are out there, educate in many different ways ...'.

Based on this, and on the information gathered during the first phase of the data collection process, additional questions were asked in the form of a second followup semi-structured interview. This procedure also allowed for a form of participant checking, as the researchers were then able to check their understanding of the content and meanings gleaned about each participant during the first interview.

\section{Participant checking}

After the researchers had analysed the data from the first two sources of data (i.e. the lifelines, collages and first round of interviews), each participant was requested to comment on the themes elicited from the data and offer their interpretation and view on the preliminary research findings; their suggestions were integrated into the data before final submission. 


\section{Data analysis and interpretation}

Data was analysed according to a constructivist-interpretivist framework. The researchers consciously prevented their bias and subjective experiences from influencing the outcome of this study; focusing, rather, on the constructed meanings created by each participant. Preliminary data analysis was done by manual coding of the data. The codes were grouped into families, and these were then briefly discussed. Subsequently, the preliminary analysis was taken to each participant for their comment and a discussion of the findings, as recommended by Cohen, et al. $(2004,120)$, as well as Northcutt and McCoy $(2004,17)$. Their comments were then integrated into the findings before the presentation of the final data.

\section{Ethical considerations}

This research study was conducted in accordance with the ethical guidelines stipulated by the University of Pretoria and as suggested by various researchers (Cohen et al. 2004, 49-72; Babbie et al. 2002, 520-526; Strydom 2000, 25-30). The following ethical issues were considered and then addressed:

- Informed consent: The three participants were informed about the aims of this study and research process before being asked whether they would like to participate in it. The respondents then signed a letter of consent that provided details on the scope of their participation.

- Confidentiality and privacy: When the participants were initially approached they were given the assurance that confidentiality, anonymity and privacy would be maintained. This information was repeated at various times throughout the research process. To facilitate that, pseudonyms were used and all identifying information removed from the data.

- Deception: At no stage in the research process were the participants deceived about the purpose of this research and the aims of this research were discussed with each participant before the research process commenced. Each participant was also provided with a copy of the consent letter that they had signed, wherein aims and processes of the research are provided in detail.

- Harm to respondents: The three participants were not harmed in any way (whether physically or emotionally) during the course of this research. And, when they felt uncomfortable, they were given the option of discontinuing their participation or changing the subject under discussion. No human rights were infringed upon during this research.

- Reporting results: The three participants were informed that the research results would be published in academic format. This was also addressed in the letter of consent. The participants were involved during the data analysis and interpretation processes and, therefore, in the reported results. The results of this research were made available to the participants for their perusal before being published. 
A major element that had to be considered in this research was the fact that the researcher had an established relationship with all three of the participants before commencing with this study. The researchers were aware that this could have ethical implications, which included researcher bias and that the respondents may have felt obligated to participate in this research. On the other hand, the existing relationships ensured a shared frame of reference, making it easier for the researchers to understand the meanings that the participants attributed to some aspects of their lives. That resulted in a strong rapport being established with the participants, which - in itself - is an important research mechanism.

The potential problems of working with participants who were known by the researchers were addressed through consciously holding an awareness of the dangers this situation held throughout the interactive processes and through researcher reflexivity. The researchers endeavoured to limit role confusion (that of friend, relative or psychologist versus researcher) through reflecting on the process of the research throughout the conversations and by clarifying the role of researcher before the data collection commenced. The researchers also used participant validation (member checking) of the findings to ensure that the respondent's voices and views were accurately portrayed. The possible perception of the participants feeling obligated to participate in this research was addressed by explicitly discussing the issue with them.

\section{FINDINGS}

\section{Overview}

\section{School}

The three participants all identified experiences at their school as being the factor that influenced their decision to take a gap year. They all reported negative feelings about their schooling (e.g. ' ... I started college because I didn't like school'; '... I was depressed the whole of high school'; 'I didn't enjoy the technical school, didn't enjoy the work and the people'). And, to an extent, their feelings had been influenced by poor relationships at school. All three participants were dissatisfied with the career guidance counseling they had received while at school (e.g. 'If they [the career counselors] gave me something more specific, they just said I'm good in all the areas, I can go and to anything').

\section{Career exploration}

All three participants reported having engaged in career exploration in various ways prior to making their final career choice and gained work experience in various fields, some of which, it later proved, was related to their final career choice; while many were not related at all (e.g. 'I worked at [an insurance firm] for 6 months selling shares, it was very boring and unsatisfying, I worked at Student Wise over weekends as a driver, I even cooked pizza's in a shopping centre for promotions ... all practical 
job exploration'; 'I also did, you know, I did the secretarial work for [an auditing firm] and I did administrative work for [an insurance firm], but I also did a bit of community work at a homeless shelter'). The three participants had chiefly relied on practical job exploration, rather than purely theoretical exploration, to aid them in their quest to decide on a career. However, all three admitted to doing research on the Internet and requesting the assistance of mentors.

The three participants all stressed the importance of studying on the tertiary level, and admitted the view that studying is a pre-requisite for having a successful career (e.g. '[studying] is still something that I want to do, that I feel I have to do'; '... I think it is important to have a degree or diploma or something to say at least you furthered yourself and bettered your knowledge of the field you are trying to go into'; 'Studying is very important because it equips you properly for a professional career if you want to be professional ... But for most people if you want to get paid properly one day, and to be able to support yourself, but then you have to study to have something behind your name').

All three participants admitted part of their motivation for taking a gap year included the need to take time to resolve their emotional uncertainty about choosing a career (e.g. ' ... I wanted to take a gap year first because I thought then at least I'm certain of what I want to study by the time I come back'; '... it was mostly killing time until I decided. I thought that I would go overseas the second time and just earn money'). Other motivators included the wish to engage in a 'constructive pursuit' while making a career decision (and allied to that, to earn money), family support, and, to a certain extent, the wish to explore the nature of the world of work in South Africa.

\section{Expectations of gap year}

The three participants had various expectations about their gap year, which served as motivators for them to decide to engage a gap year; they expected to earn money during their gap year and have the opportunity to gain work-related experience (e.g. 'I thought that I would go overseas the second time and just earn money').

The three participants had an expectation about the nature of the work they would engage in, which included the thought that they may struggle to find a job and they would probably engage in many short-term jobs throughout their gap year (e.g. 'To start off, I was looking for anything that I could do to get a salary!'; '... I think because I was expecting, because you always hear the people at work, in one job for a month and have to go somewhere else for a month ...'). Further, they each had an expectation of personal growth and skill development, as well as the opportunity to explore different career options - though these expectations were less prominent.

\section{Results}

The participants each reported different results of their gap year experience and all admitted discrepancies in their expectations of what they would experience and what 
they ended up experiencing. For example, the participants who went to the UK did not earn as much money as they had expected, nor did they have as much opportunity for travel (e.g. 'I thought I was gonna have, I was gonna do more partying and fun things, but I did have fun things, but I didn't do any partying. I expected to go and see more places, and I expected to at least go abroad to Europe, around there and maybe even just to farms and I didn't do that, so that was a bit of a disappointment'). There was also a difference in expectation with regard to the nature of the employment they had hoped to find and what they ended up doing (e.g. ' ... I was hoping to get a teacher's assistant appointment position, but I didn't get that, so I continued looking for something in that line then I just got a job through the employment agency and stayed there').

The three participants all reported an increase in their independence and confidence level, and having gained insights into their own personality and relationships with others. In addition, they experienced an increase in life-skills related to taking care of themselves, budgeting of their finances, and interpersonal skills (e.g. 'I would say before we went overseas, I mean we obviously had our parents to do everything for us ... it actually teaches you how to control your money and how to save and things like that as well'; '... if you don't make friends you are not going to have any friends, I had to come out of my shell a bit').

In the final analysis, the 'result of the gap year' needs be assessed in relation to the career decision-making process. The three participants reported that the gap year did not lead them directly to make a decision on their career; rather, that experience had helped them improve their self-confidence and, thereby, their ability to make a decision on their career. One of the participants commented ('... I didn't think I would be able to do [the gap year] and I thought I would get lost and get scared and, surprisingly, I found my way and I was pretty confident in doing it'). However, one participant was of the opinion that the gap year had not helped him make a new career decision; it merely facilitated a career path that he selected while still in high school.

\section{Feelings about the gap year}

The three participants reported both positive and negative feelings about their gap year experience. The positive feelings relate to their increased life experience and personal growth (e.g. ' ... [the gap year] helped me realise what I wanted because I didn't know what I wanted, I was young, I was just out of school, I just chose the first thing that came long, I didn't realise that that's gonna be for the rest of my life. So ja, I did grow a lot personally inside'; 'I loved the people I met, the friends I made, I loved going to the places that I went to and seeing many things ...'). The negative feelings relate to specific experiences dealt with during the gap year, such as stressrelated to work and financial concerns (e.g. 'I would go see more, maybe spend a bit more of that money while I was there. And I would have, I think as much as I came out of my shell, I think I would have came out of it more, been a bit more confident and a bit more outgoing than I was'; 'what happens when you go into a job where 
you are in over your head, you just get more stressed than anything and that's just a symbol of my working environment that I was in'; 'It was very difficult, running out of money and having to eat two-minute noodles all the time because they were cheap'). However, despite having negative feelings about certain aspects of their gap year, on the whole, none of the participants regret having chosen that experience.

Figure 1 is a graphic presentation of the themes and sub-themes relevant to the topic of the gap year that arose from the content analysis:

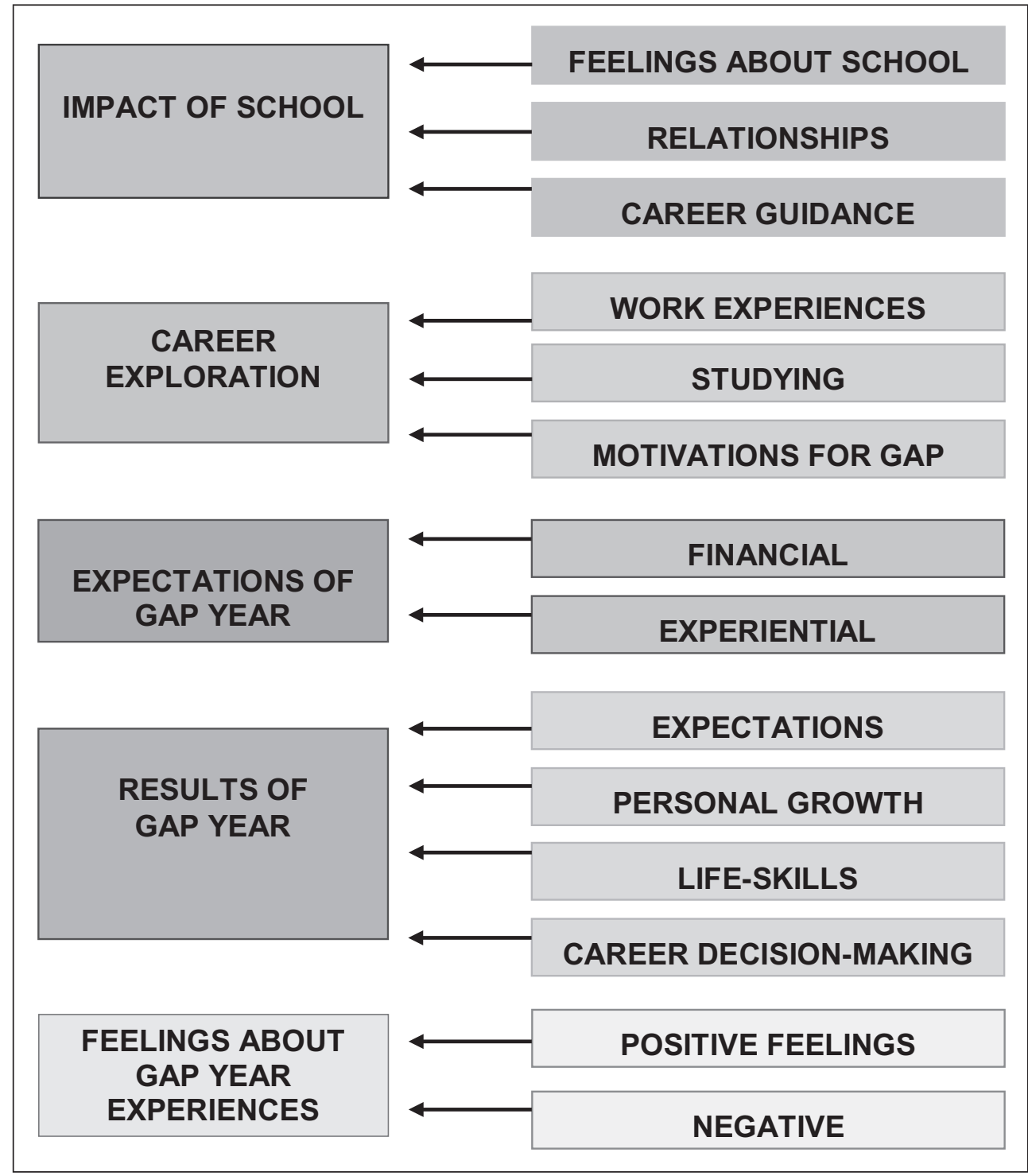

Figure 1: Representation of themes and sub-themes 


\section{Discussion}

\section{Impact of school}

The issue identified by the three participants related to inadequate career guidance being provided them while they were still in school is confirmed by Jones' study (2004b, 39), which found that a lack of career-related advice and guidance influences gap year participation among school-leavers in the UK. Likewise, the participants in this study experienced problems with regard to a lack of guidance, a lack of personal attention during group testing and inconclusive results - all of which contributed towards their career indecision. However, as pointed out by Savickas (1995, 3), career indecision can be deemed a normal occurrence for young people who have not yet formed their personal identity.

\section{Career exploration}

The three participants in this study showed a tendency to engage in practical career exploration. Career exploration is an important and age-appropriate developmental task of the participants engaged in a gap year, and the career decision-making process is a developmental task linked to the stage of exploration (Super, Savickas and Super 1996, 131-135; Bester 2004, 293; Super and Hall 1978, 334). The focus by participants on the importance of studying is understandable in terms of the context of the participants, who all are from the middle-class society in South Africa, which holds to the thought that it is held in high esteem to have educational qualifications.

When discussing the participant's motivations for engaging in a gap year, it is important to note that dealing with career indecision is common amongst school leavers and Savickas $(1995,3)$ views that indecision as an expression of the hesitation before the transformation; something that occurs as personal identities are forged and consolidated. That these three participants wished to engage in constructive pursuits during their gap year is in contrast with the findings of Jones (2004b, 38), who states that the most common motivator in the UK is to experience the world - to merely take a break from work or study. In relation to that, he identified the student's educational context as being the most important factor to influence the decision for young people from the UK to decide to take a gap year. However, it is not within the scope of this study to discover whether that is also the case in South Africa. Jones (2004b, 38) also identified the influence of the family as being a deciding factor; which is echoed in this study. It can be inferred from the differences revealed in the relevant literature that gap year participants from South Africa engage in such activity for reasons different than those from the UK. It would appear that South Africa's youth participate in a gap year to the benefit of their career; whereas for youth from the UK the focus is on having different experiences.

\section{Expectations of the gap year}

The expectation of the three participants in this study was to earn money and gain work experience; which is confirmed in the study by Jones (2004b, 34), when he found that young people in the UK focused on the experiential aspects when deciding 618 
whether to take a gap year. The fact that participant expectations about personal growth were not prominent is also confirmed by Jones (2004b, 38), who states that, while the participants are aware of the aspect of gaining life-skills, that it is not an important motivator.

\section{Results of the gap year}

Despite the discrepancies between the expectation and the experience of the participants, knowledge of the world of work (which the participants gained through their experiences) has been identified by Super and Hall $(1978,340)$ as one of the variables that leads to career maturity. Therefore, despite the differences between expectation and experience, the experience could still be regarded as valuable in terms of personal growth.

For the three participants in this study, the most compelling result of the gap year experience was the level of personal growth that took place. Super (1990, 225-226) suggests that personal growth, in terms of increased maturity and skills gained, is an important part of career development. The skills that participants gained influenced their abilities to cope with the developmental task of the career decision-making process, and, therefore, influenced their career maturity (Mitchell and Krumboltz 1996, 237-242; Super 1990, 213). However, all three participants acknowledge that, as individuals, they are still developing; which emphasises the dynamic nature of career development, as described by Super (1990, 225-226) as well as Super and Hall $(1978,334)$. The personal growth and increased maturity that takes place is cited by Jones $(2004 a, 2-3)$ as a commonly acknowledged advantage of the gap year in the UK. The additional life skills that participants reported (budgeting their money, taking care of themselves etc), is echoed in the findings of Jones (2004b, 58), who established that improved life and career skills were an advantage of taking a gap year. Mitchell and Krumboltz (1996, 237-242) also point out that task approach skills, such as the life-skills, gained by the participants are an important factor in the career decision-making process. This statement is echoed by Picklesimer, Hooper and Ginter (1998, 272-274), who argue that life-skills are necessary to meet the demands placed on young people, thereby implying that increased life-skills, within their own right, can be seen as a factor that contributes toward career maturity.

While the three participants felt that taking a gap year did not directly lead to a career decision, they did find that it improved their confidence and 'readiness' to deal with that decision. That ties in with the theory of Super, which states that increased maturity is characterised by the ability to make a career decision (Super and Hall $1978,340)$. The sub-theme of personal growth is therefore strongly related to the career decision-making ability.

\section{Feelings about the gap year}

The three participant's feelings about their gap year are based on their individual subjective experience and perception, which reflect the complexity of the gap year phenomenon, as the gap year influences not only the participant's social and socioeconomic worlds but also their emotional world. 


\section{CONCLUSIONS}

The findings of this study indicate a general trend of negative feelings about the career guidance the participants in this study received while at school, which may indicate misconceptions of the purpose and practice of career guidance; however, that did not impact negatively on their eventual decision to study further after graduating from school. Although inadequate career guidance may contribute to indecision as to which career to follow amongst school leavers, it would appear that many young people currently engage in practical job exploration (engaging in various forms of short-term work after school) more often than in theoretical job exploration (such as online research or speaking to practitioners within various careers). The suggestion did emerge during this study that the three participants do believe that having a qualification on tertiary education level will improve their chances of finding employment and earn a higher salary. However, the gap year provides opportunity to decide whether or not to study and, in certain cases, helps students earn money to finance their studies. It may be inferred that other young South Africans from a similar demographical background to that of the three participants in this study may have similar feelings about the gap year.

It would appear that an interaction of various factors influence young people's choice to engage in a gap year; which may include: family support, expectations about the gap year and the possibility of career exploration. However, as indicated by the three participants in this study, the primary motivator for taking a gap year is to take time out before making a decision on a career to follow. Therefore, it can be said that experiencing career indecision may be an important motivator for young people to engage in a gap year. It would also appear that earning money is an important motivator for people who chose to take a gap year, with certain students choosing to work overseas, to earn money in a stronger currency.

The findings indicate that, while people have different expectations and motivations for engaging in a gap year, the net result of the phenomenon is similar; the gap year has a positive influence on personal growth and the acquisition of lifeskills, leading to increased career maturity. When considering the value of the gap year phenomenon, this study suggests that the main factor to impact on the career decision-making process is that it allows young people time to mature.

Though it would appear that young people's expectations of the gap year are partially met, certain discrepancies do exist between expectations of the world of work and the actual experiences of people entering the job market. And despite differences in the type of activities experienced during the gap year (i.e. those taken overseas and those taken locally) the outcome, in terms of personal growth, is similar.

Finally, the findings of this study suggest that young people may find that the gap year is meaningful in terms of facilitating personal growth and, more specifically, gaining independence and greater life-skills. Despite certain negative aspects, the supreme benefit of the gap year is in terms of career development. To what extent do these findings address the primary research question of this study? 


\section{HOW DOES THE GAP YEAR INFLUENCE CAREER DECISION-MAKING?}

The career decision-making process is complex, with various factors interacting to lead one to a final decision. The result of this study indicates that the gap year has an indirect impact on a career decision-making process in the following ways:

Firstly, the gap year offers young people the opportunity of the time to resolve their indecision on a career path, while gaining career maturity. While career indecision affects many people at some stage in their life, it is most prevalent among young people who have just graduated from school. As career maturity is an important aspect of the career decision-making process, the gap year may be the answer to young people's dilemma of indecision.

Secondly, the gap year facilitates personal growth in confidence and selfknowledge. Those aspects also contribute to greater career maturity; increased selfconfidence leads to the ability to make a decision and to trust that the decision is the correct one.

Thirdly, experiences during the gap year teach people about the world of work and expose them to different work environments; which leads to an increase in selfknowledge about personal interests and preferences. Knowledge about the world of work is also viewed as a characteristic of career maturity; which contributes towards making a career decision. For example, when the young people find themselves in a work environment that they don't enjoy, it motivates them to analyse that environment and move to a new environment.

In summary, it would appear as though the gap year increased the participant's career maturity. The final element of the maturation process is that a decision on which career to follow is made. It is acknowledged that this study is limited in terms of the small size of the sample that was applied, which - in turn - limits generalisability; however, it can be inferred that the gap year could be beneficial to young people who are experiencing career indecision, have a need to experience the world and workplace, and who wish to earn money and gain experience before choosing a career to follow. Though, it must be noted, while the gap year is not a 'cure all' for career indecision, career counselors and school guidance programmes may consider offering it as a possibility to broaden young people's horizons, by incorporating the gap year as being a valid element within the career decision-making process.

The researchers acknowledges that the results of this research were predominantly positive, which may not reflect the reality for all gap year participants. It should be kept in mind that the participants were known to the researchers prior to the research being conducted, and while this had a positive influence on the rapport between researcher and participant, as well as their willingness to participate, it may also have influenced the findings to some degree in terms of the participants being eager to please. Despite this, it cannot be denied that the participants in this study were very positive about the benefits of the gap year to their individual career development. 


\section{REFERENCES}

Asmal K. 2004. South Africa's brain drain dilemma. BBC News April 19. Available at: http:// news.bbc.co.uk/go/pr/fr/-/1/hi/world/africa/3629657.stm. (Accessed on 5 October 2005).

Babbie, E., J. Mouton, P. Vorster and B. Prozesky. (Eds). 2002. The practice of social research. Cape Town: Oxford University Press Southern Africa.

Bester, S. E. 1999. Die ontwerp van ' $\mathrm{n}$ postmodernistiese model vir beroepsvoorligting. Ph.D. thesis. University of Pretoria.

- 2004. Career development. In Keys to educational psychology, eds. I. Eloff and L. Ebersöhn, 289-313 Cape Town: UCT Press.

Brott, P. E. 2004. A constructivist look at life roles. The Career Development Quarterly 153(1): 138-149.

Cohen, L., L. Manion and K. Morrison. (Eds). 2004. Research methods in education. Fifth edition. London: Routledge Falmer.

Fischman, G. E. 2001. Reflections about images: Visual culture, and educational research. Educational Researcher 30(8): 28-33.

Gose, B. 2005. If at first they don't succeed .... Chronicle of Higher Education [Electronic version] 51 (48): A30-A32.

Henning, E., W. van Rensburg and B. Smit. 2004. Finding your way in qualitative research. Pretoria: Van Schaik Publishers.

Jones, A. 2004a. Gap year: Make or break time. Guardian Unlimited. Available at: http:// education.guardian.co.uk/students/gapyear/story/0,12763,1269375,00.html. (Accessed on 12 February 2006).

- 2004b. Review of gap year provision. Research Report RR555. London: University of London.

Kvale, S. 1996. Interviews: An introduction to qualitative research interviewing. Thousand Oaks, California: Sage Publications.

Margolis, E. 2000. Class pictures: Representation of race, gender, and ability in a century of school photography. Visual Sociology 14(1): 7-36.

Mitchell, L. K. and J. D. Krumboltz. 1996. In Career choice and development, eds. D. Brown and L. Brooks, 233-280. San Francisco: Jossey-Bass Publishers.

Mkhize, N. J and K. Frizelle. 2000. Hermeneutic-dialogical approaches to career development: An exploration. South African Journal of Psychology 30(3): 1-8.

Niles, S. G. and J. Harris-Bowlsbey. 2002. Career development interventions in the 21st Century. New Jersey: Merrill Prentice-Hall.

Northcutt, N. and D. McCoy. 2004. Interactive qualitative analysis: A systems method for qualitative research. Thousand Oaks: Sage Publications.

Novoa, A. 2000. Ways of saying, ways of seeing - public images of teachers $\left(19^{\text {th }}-20^{\text {th }}\right.$ centuries). Paedagogica Historica 36(1): 21-52.

Picklesimer, B. K., D. R. Hooper and E. J. Ginter. 1998. Life-skills, adolescents, and career choices. Journal of Mental Health Counselling 20(3): 272-282.

Piddock, C. 2004. Taking time out. Career World 33(3): 6-9.

Robinson, V. 2003. Brain drain to brain gain. Mail \& Guardian January 22. Available at: http://www.queensu.ca/samp/sampresources/samppublications/pressarticles/2003/ drain.htm. (Accessed on 5 October 2005).

Savickas, M. L. 1993. Career counselling in the postmodern era. Journal of Cognitive Psychotherapy: An International Quarterly 7(1): 205-215. 
- 1995. Constructivist counselling for career indecision. The Career Development Quarterly 43(4): 363.

- 2003. Advancing the career counselling profession: objectives and strategies for the next decade. Career Development Quarterly 52(1): 87-96.

Schurink, E. M. 1998. In Research at grass roots: A primer for the caring professions, ed. A. S. de Vos, 239-281. Pretoria: Van Schaik Publishers.

Simpson, K. 2005. Dropping out or signing up? The professionalisation of youth travel. Antipode 37(3): 447-469.

Smith, J. A. 1995. Semi-structured interviewing and qualitative analysis: an introduction. Available at: http://www.psych.ucalgary.ca/CourseNotes/PSYC413/Assignment/LabManual/proj4/intro.html. (Accessed on 6 February 2006).

Smit, B. 2001. Primary school teachers' experience of education policy change in South Africa. Ph.D. thesis. University of Pretoria.

Strydom, H. 2000. Ethical aspects of research in the caring professions. In Research at grass roots: A primer for the caring profession, ed. A. S. de Vos, 23-36. Pretoria: Van Schaik Publishers.

Super, D. E. and D. T Hall. 1978. Career development: Exploration and planning. Annual Review of Psychology 29(1): 333-372.

Super, D. E. 1990. A life-span, life-space approach to career development. In Career choice and development, eds. D. Brown and L. Brooks, 197-261. San Francisco: Jossey-Bass Publishers.

Super, D. E, M. L. Savickas and C. M. Super. 1996. The life-span, life-space approach to careers. In Career choice and development, eds. D. Brown and L. Brooks, 197-261. San Francisco: Jossey-Bass Publishers.

Tolbert, E. L. 1980. Counseling for career development. Second edition. Boston: Houghton Mifflin Company.

Yin, R. K. 2003. Case study research: Design and methods. Third edition. Thousand Oaks: Sage Publications. 